\title{
INNOVATIVE SUPPLY CHAIN SOLUTION FOR INDIAN AUTOMOBILE MANUFACTURING SECTOR: A CASE STUDY
}

\author{
Sanjay Choudhary ${ }^{* 1}$, Deepanshu Arora ${ }^{* 2}$, Sunil Kumar Jakhar ${ }^{* 3}$, \\ Krishna Nandan ${ }^{* 4}$ Amogh Sharma*5 \\ , ${ }^{*}, 2,3,4,5$ Assistant Professor, Department of Mechanical Engineering, Vivekananda Institute of \\ Technology, Jaipur, Rajasthan, India
}

Article DOI: https://doi.org/10.36713/epra7336

DOI No: 10.36713/epra7336

\begin{abstract}
In Indian Automobile Industry for heavy \& commercial vehicle segment, manufacturers always face the major problem of supply chain management. As manufacturer follows any kind of solution scheme, they do not find very improved results, so for Indian condition an innovative solution of supply chain is required. The study is based on using In Bound \& Out Bound Strategy together providing an edge to come over the Supply chain management problem.
\end{abstract}

\section{INTRODUCTION}

Ashok Leyland is a commercial vehicle manufacturing company based in Chennai, India. Founded in 1948, the company is one of India leading manufacturer of commercial vehicles, such as trucks and buses, as well as emergency and military vehicle. Operating six plants, Ashok Leyland also makes spare parts and engines for industrial and marine application. It sells about 60000 vehicles and about 7000engine annually. It is a second largest commercial vehicle company in India the medium and heavy commercial vehicle segment with a market share of $28 \%$ (2017-2018). Ashok Leyland is the second technology leader in the commercial vehicles sector of India behind Tata Motors; in 1997 the companies launch the country first CNG bus.

NEED OF SUPPLY CHAIN MANAGEMENT The company (Ashok Leyland) was facing the huge task of integrating its entire supply chain and at the same time it had to reduce its costs, inventory, and improve customer satisfaction. Rising raw material cost was a serious concern for the company. Therefore, Ashok Leyland decided to streamline its supply chain process and the company started its SCM project OSCARS (Optimizing Supply chain And Rationalizing sourcing) to optimize its supply chain and rationalize its sources.

\section{IN BOUND SUPPLY CHAIN}

To reduce costs and to improve the inbound supply chain Ashok Leyland introduced the project OSCARS (Optimizing Supply chain And Rationalizing sourcing) which includes supplier partnership, vendor base rationalization supply tiers, inventory optimization through JIT total cost management logistics initiatives sourcing and global sourcing. 


\section{EPRA International Journal of Research and Development (IJRD)}

The Basic Principles of OSCARS

1. Vendor base rationalization

2. Single window system

3. Supplier tier

4. Just in time (JIT)

5. Logistic initiative

6. E-sourcing

Single window system: The strategic sourcing and "Corporate Quality Engineering" (CQE) teams jointly formed the single window system bringing with them specialized commercial and technical knowledge. For the supplier this had created a convenient single point contact with AL for sharing drawing, for negotiating prices and long-term business volumes and consultancy on quality to management issues.

Supplier tier (any one of two or more competitors tie one another): AL pruned its panel of direct suppliers thorough tiring and system buying. Under this $\mathrm{AL}$ dealt directly with tier one suppliers who in turn were supported by tier two and tier three suppliers. Tear down studies and value engineering analyzed the constitution and composition of a part to prune cost through substitution reduction or elimination of material /sub-assemblies without affecting quality and performance.

Just in time (JIT) AL focused on JIT approach for high value /high volume items and low-cost logistics for low value high volume items. Project OSCARS brought about a few fundamental changes. The push system which means "let us make all we can just in case we need". This system given a way to pull system which means "make what the customer need when he needs it". Each stage produced only as much as the next stage needed. This resulted in saving of Rs. 8.5 crore a year and a lean supply chain.

Logistic Initiative: These initiatives included transport-based rationalization, enhancement of truckload, space and route optimization which has benefited the company by saving its transportation cost.

E-sourcing: E-sourcing included global benchmarking gain through bidding, identification of cost competitive sources, introducing best sourcing practices, increasing efficiencies, and minimizing costs, improving bottom line of the value chain. All these activities have saved $11.5 \%$ of total material cost.

\section{OUT BOUND SUPPLY CHAIN}

A customer survey and a study of benchmarks had come out with three major parameters for service level targets which are order to delivery time, reliability of deliveries and availability of order status information. The customer could accept delivery in 5 days from the date of payment for regular models for multi axle vehicles the promised period was two to four weeks. Tight pipeline inventory norms were set for different models and markets and were met through a new three tier distribution network. Plant sales yards acted as national pools to hold rare models and excess of regional requirement. Next tier was made regional stock pools, which ensured just in time supplies to all regional sales offices.to understand customer needs and -assimilate the knowledge. AL also built a marketing information system (MIS) to monitor the trends and forecast demand from the input dealers and field executives. The Regional office worked towards continuous improvement in the products and marketing.

Table 1: List of AL Regional Part Warehouses

\begin{tabular}{|l|}
\hline REGIONAL PART WAREHOUSES \\
\hline Chennai \\
\hline Bangalore \\
\hline Hyderabad \\
\hline Trivandrum \\
\hline Pune \\
\hline Ahmadabad \\
\hline Delhi \\
\hline Jaipur \\
\hline Kanpur \\
\hline Nagpur \\
\hline Dhanbad \\
\hline
\end{tabular}

Table 2: List of AL Regional Offices

\begin{tabular}{|l|}
\hline REGIONAL OFFICE \\
\hline Gurgaon- (Middle India) \\
\hline Jaipur (Rajasthan) \\
\hline Lack-now (UP and Uttaranchal) \\
\hline Calcutta (East) \\
\hline Mumbai (Maharashtra and Goa) \\
\hline Ahmadabad (Gujarat) \\
\hline Nagpur (Central) \\
\hline Chennai (Tamilnadu) \\
\hline Bangalore (Andhra Pradesh) \\
\hline Trivandrum (Kerala and Karnataka \\
\hline
\end{tabular}




\section{EPRA International Journal of Research and Development (IJRD)}

Volume: 6 | Issue: 6 | June 2021

- Peer Reviewed Journal

As the location constraints to deliver the end product at various location in all over India, AL required a solution scheme which should have a combination of traditional supply chain management system includes with some innovative solution. To follow such dynamic condition, a solution and innovative approach is proposed in this work. The detailed flow chart of supply chain is being representing in the following figure. The introduction and provision of regional parts warehouse is required to maintain such type of supply chain solution. Here the assembled products are required at various end location, the unique item is the engine is required to complete the full assembly. As the engine manufacturing is required a huge investment therefore it can be arranged at a single location. So that the one engine manufacturing unit is same as available in the case of AL.

The engine division deliver the engine to the regional part warehouse, same as the regional raw material suppliers supply various raw material to the warehouse required to the product assembly. And the various Assembly units are being established to fulfil the local demand of the various region. The proposed structure of the full AL product supply chain is being represented in the following figure. The typically we can see the various locational distance to the center warehouse, and the distance to the warehouse to the assembly units are the main constraints of the problem. The optimum routing will be the focused target of the current study. So that, with the minimum investment all the deliveries can be conform.

The need of optimum routing is important to maintain the production cost for the market competition. Here the routing is the NP hard nonlinear structure due to the complexity and the dynamicity of the supply chain structure. To solve and optimize the proposed approach, evolutionary algorithms can be utilized.

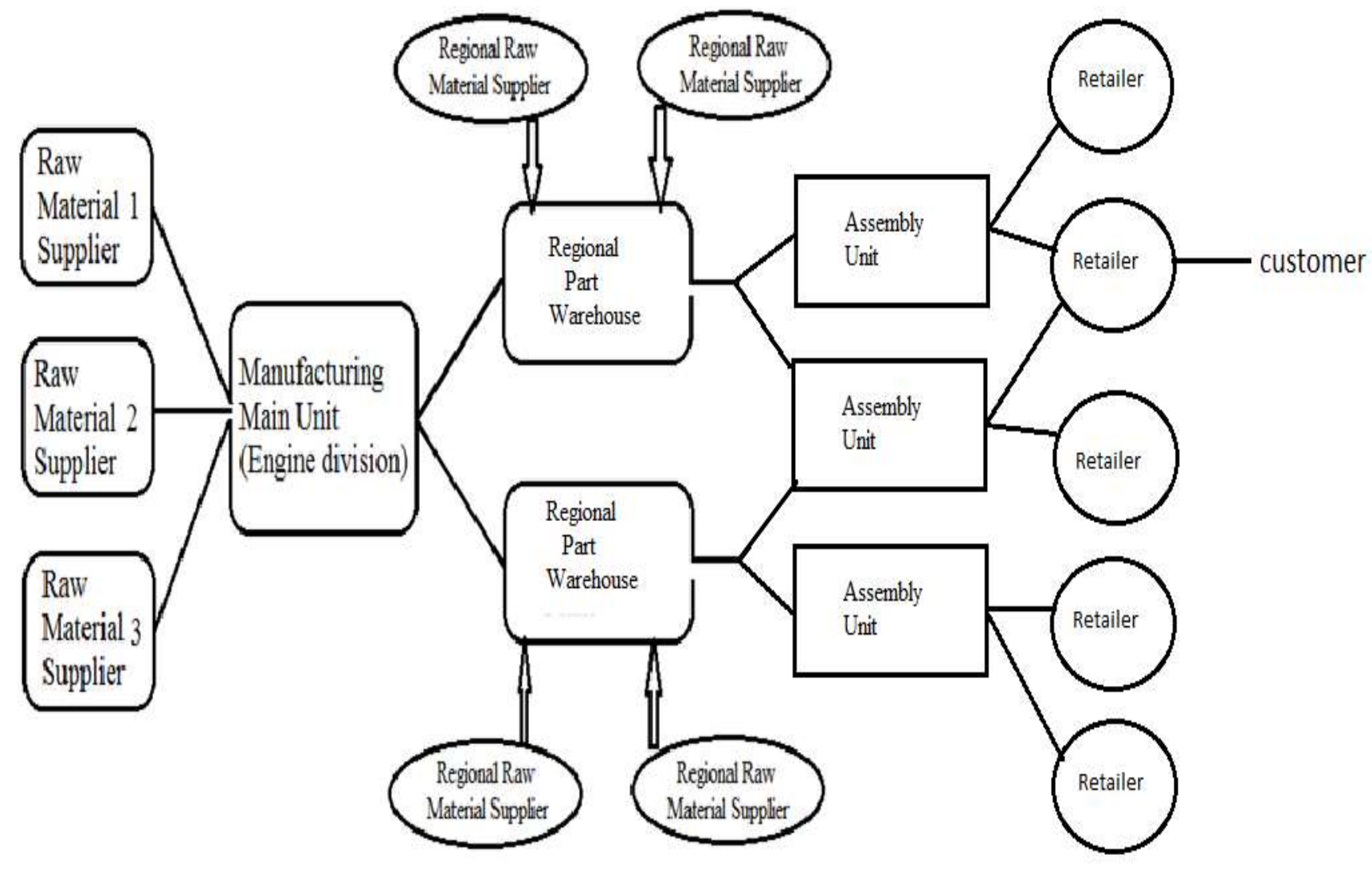

\section{EVOLUTIONARY METHODS FOR OPTIMUM SCM SOLUTION}

In the modern time, the algorithms based on evolutionary approach based on population and random selection are utilized to solve the non-linear type of complex problem. Because of the functionality and the ability to handle the multi targe and multi-objective optimization problem, such approaches have a huge scope in the field of finding optimum solution or supply route. The optimum 


\section{EPRA International Journal of Research and Development (IJRD)}

route guaranty to the minimum investment of time and money for fulfill all the demand on due time.

The Genetic Algorithm (GA), Particle Swarm Optimization (PSO), Ant colony optimization (ACO) are such kind of evolutionary approaches, using them we can optimize the results of the proposed supply chain solution. As the previous researchers done their research work with the application of GA with manufacturing scheduling one of the kinds of nonlinear problem. Their research work shoes the random selection criteria-based approach like GA provides vary attractive results, also integrate with the problem very easily though the use of MATLAB programming

\section{CONCLUSION}

The present focused over the use of combination of traditional and modern methods for the promising supply chain in Indian sub-continent for the supply of heavy automobile products. The proposed approach focused over the use of regional warehouse at the center of inbound and outbound supply nodes, so that multiple regional warehouses can fulfill the need to multiple assembly units at constant rate and with fail. Furthermore, the for the optimum routing purpose the evolutionary algorithms can be used. The GA is one of the kinds of population based evolutionary optimization technique, can use to solve the routing problem of the proposed system. It has very great ability to integrate with the nonlinear type of problem, and the use of the problem is also very easy through the MATLAB platform. The final solution highlights the optimum requirement of the resources to fulfill the reginal demand of the AL heavy automobile. That will also help to the organization by minimizing the production cost and in increasing the revenue.

\section{REFERENCES}

1. Ballou, R. H. (n.d.). "Logistics, Supply Chain \& Transport Management Program".

2. Badenhorst-Weiss, I. M, "Strategic supply chain framework for the automotive industry". African Journal Of Business Management Vol. 4(10), pp. 2110-2120, (18 August, 2010).

3. D Arora, L Dhuria, M Choudhary,' Use of Artificial Intelligence Techniques to Solve Multi-target Flow Shop Scheduling Problem', International Journal of Research in Engineering, IT and Social Science Vol. 9, No. 3, PP. 128-133, 2019.

4. Deepanshu Arora \& Gopal Agarwal 'Meta-Heuristic Approaches for Flow Shop Scheduling Problems: A Review' International Journal of Advanced Operations Management, Inderscience, Vol. 8, No. 1, PP. 1-16 2016.
5. Deepanshu Arora \& Gopal Agarwal 'Application of GA and PSO for Flow-Shop Scheduling Problem 'International Journal of Emerging Technologies and Innovative Research. Vol.4, No. 9, PP.240-247, 2017

6. Koskela, R. V. (26-28 July 1999). "Roles of Supply Chain Management in Construction". Proceedings IGLC-7, University of California, Berkeley, CA, USA, 133-146.

7. Muriati Mukhtar, A. M. (n.d.), "Supply Chain Relationship Structures as Scenarios for Simulation”.

8. Report, A. L. "Passion for Engineering". (2006-07).

9. Survey. (n.d.). "Driving on the Road to success Ashok Leyland". 24x7learning

10. VijayR. Kannan, K. C. (Omega 33 (2005)). “Just In Time, Total Quality management, And Supply chain Management: Understanding Their Linkages and Impact on Business Performance”. Elsevier, 153 162 